\title{
The appropriate dose of propofol for anesthesia induction in morbidly obese patients
}

\author{
Guiping Xu, Nannan Qiao, Yangyang Pan, Alimujiang Simayi, Nan Chen \\ Department of Anesthesiology, People's Hospital of Xinjiang Uygur Autonomous Region, Urumqi, China \\ Contributions: (I) Conception and design: G Xu, N Qiao; (II) Administrative support: G Xu; (III) Provision of study materials or patients: Y Pan; \\ (IV) Collection and assembly of data: Y Pan, N Chen, A Simayi; (V) Data analysis and interpretation: N Qiao, Y Pan; (VI) Manuscript writing: All \\ authors; (VII) Final approval of manuscript: All authors. \\ Correspondence to: Guiping Xu. Department of Anesthesiology, People's Hospital of Xinjiang Uygur Autonomous Region, Urumqi, China. \\ Email: xgpsyl@126.com.
}

Background: To investigate the optimal dose of propofol in patients with morbid obesity when the anesthetic induction dosage is calculated based on lean body weight (LBW).

Methods: Forty morbid obese patients with body mass index (BMI) $\geq 35 \mathrm{~kg} / \mathrm{m}^{2}$ were randomly divided into two groups: B and M. The sequential method was used in group B to study the EC50 and $95 \%$ confidence interval (CI) that met a bispectral index (BIS) value of $<50$ (the initial dose was set at $2.5 \mathrm{mg} / \mathrm{kg}$ ). The sequential method was used in group $M$ to obtain the EC50 and $95 \%$ CI (the initial dose was set as $3.0 \mathrm{mg} / \mathrm{kg}$ ) satisfying the mean arterial pressure (MAP) fluctuation margin of $>40 \%$. The optimal dose interval of propofol was obtained by synthetically analyzing the results of the two-sequence method.

Results: There was no significant difference in the general condition between the two groups $(\mathrm{P}>0.05)$. There was no significant change in vital signs from when patients entered the operating room to when sufentanil was infused $(\mathrm{P}>0.05)$. The probit model of group B was $\mathrm{Y}=-5.411+2.343 \mathrm{X}$, the EC50 of positive reaction with BIS $<50$ was $2.310 \mathrm{mg} / \mathrm{kg}$, and $95 \%$ CI was $1.850-2.883 \mathrm{mg} / \mathrm{kg}$. The probit model in the $M$ group was $\mathrm{Y}=3.275-0.918 \mathrm{X}$, the EC50 of positive reaction that reached $>40 \%$ of the whole process of anesthetic induction was $3.567 \mathrm{mg} / \mathrm{kg}$, and $95 \%$ CI was $1.233-7.165 \mathrm{mg} / \mathrm{kg}$.

Conclusions: The appropriate dosage of propofol was $2.310-3.567 \mathrm{mg} / \mathrm{kg}$ when the anesthetic induction dosage for patients with morbid obesity was calculated based on LBW. With this dose, the depth of intubation is satisfactory and the hemodynamics are stable.

Keywords: Morbid obesity; induction of anesthesia; propofol; appropriate dose

Submitted Nov 28, 2019. Accepted for publication Jul 13, 2020.

doi: 10.21037/apm-20-1223

View this article at: http://dx.doi.org/10.21037/apm-20-1223

\section{Introduction}

A morbidly obese person is one with a body mass index (BMI) of $35 \mathrm{~kg} / \mathrm{m}^{2}$ or more. China was found by the global population weight survey to have one of the most morbidly obese populations in the world (1). At present, a single dose of propofol is used clinically to induce anesthesia. However, the change in pharmacokinetics of propofol in morbidly obese patients means the clinical medication mode is significantly different to that of patients of a normal weight (2). Dong et al. (3) determined the PK and pharmacodynamics (PD) of propofol for anesthesia induction in morbidly obese (MO) subjects (BMI $>35 \mathrm{~kg} / \mathrm{m}^{2}$ ) at two dosing regimens [i.e., dosing based on TBW (total body weight) and LBW (lean body weight), respectively]. Their study showed that EC50 in Pharmacodynamics parameters of morbidly obese patients was significantly reduced compared with patients of normal weight, suggesting that increased brain sensitivity to propofol in morbidly obese patients. According to the conventional instructions, the calculation of propofol induction dosage 
based on TBW can lead to overdose in morbidly obese patients. By using the time to loss of consciousness (syringe drop as the marker) as the pharmacodynamic endpoint, Ingrande et al. (4) proposed that LBW was the best scalar for anesthesia induction with propofol in MO subjects. However, it has also been suggested that the calculation of induced dosage based on LBW is often insufficient. The optimal standard of the induced dose of propofol for general anesthesia in morbidly obese patients is yet to be determined. This study therefore aimed to explore the appropriate dose of propofol for anesthesia induction in patients with morbid obesity through a sequential method with the goal of providing a reference for clinical anesthesia medication for those patients.

We present the following article in accordance with the CONSORT reporting checklist (available at http://dx.doi. org/10.21037/apm-20-1223).

\section{Methods}

\section{Clinical data}

All procedures performed in this study involving human participants were in accordance with the Declaration of Helsinki (as revised in 2013). This study received approval from the ethics committee of Xinjiang Uygur Autonomous Region People's Hospital (No.: 17-257-KY), and informed consent was signed by the patients and their families. Included in the study were a total of 40 patients with morbid obesity who underwent elective surgery in Xinjiang Uygur Autonomous Region People's Hospital in the period between March 2017 and May 2018 and were randomly divided into group B and group $M$ using the number table method, with 20 patients in each group. Among the patients were 16 males and 24 females, aged between 30 and 55 years old, with weights ranging from $35-42 \mathrm{~kg} / \mathrm{m}^{2}$. None of the patients had experienced serious cardiopulmonary disease, endocrine, liver, or kidney dysfunction, or electrolyte abnormalities before surgery. Patients with preoperative mental abnormalities, long-term use of analgesic and sedative drugs, drug abuse, opioid addiction, long-term drinking history, general anesthesia contraindication, and expected airway difficulties were excluded.

\section{Research process and anesthetic method}

\section{Research process}

In anesthesia induction, the conditions of sufficient anesthetic depth and the stability of the cardiovascular system must be taken into account. In this study, the dose of propofol at a sufficient anesthetic depth in group B was determined through the modified Dixon sequential method, and group $M$ served in determining the dose of propofol to ensure the stability of the cardiovascular system, with the ultimate aim of identifying the optimal anesthetic induction dose in patients with morbid obesity. The criteria for the two sequential methods were as follows: in group B, bispectral index (BIS) value $<50$ was considered as a positive reaction (5-7), while in group $M$, a mean arterial pressure (MAP) fluctuation range of anesthesia $>40 \%$ was considered a positive reaction $(8,9)$. The study steps were as follows: group B had an initial dose set to $2.5 \mathrm{mg} / \mathrm{kg}$ (according to reference and preliminary experiment), and the difference between adjacent doses was 1.25 times.

Following a positive reaction, the propofol dose of the next patient would be reduced by 1 grade of a propofol dose. Conversely, following a negative reaction, the next patient would receive a higher dose. The initial dose in group $M$ was set at $3.0 \mathrm{mg} / \mathrm{kg}$ (as determined by reference and pre-experiment). The study process was repeated in group B. Finally, the suitable dose interval of propofol was obtained by a comprehensive analysis of the results of the two sequential methods.

\section{Anesthetic method}

Preoperative medication was not administered to any of the patients. $\mathrm{SpO}_{2}$, electrocardiogram (ECG), invasive blood pressure (BP), and BIS values were routinely monitored after admission, and peripheral veins were opened. Three minutes prior to anesthetic induction, $5 \mathrm{~mL} / \mathrm{kg}$ of prefilled balance solution was used, and pure oxygen was administered by mask for $3 \mathrm{~min}$. At the beginning of anesthetic induction, sufentanil citrate (the concentration of effector chamber was set at $0.5 \mu \mathrm{g} / \mathrm{mL}$ ) was injected into all patients by target-controlled infusion (TCI) pump (Beijing SLGO Medical Technology Co., Ltd., Minto parameter). Once the concentration of sufentanil citrate reached a stable level and BIS value remained stable, a single intravenous injection of propofol (produced by Fresenius Kabi Austria $\mathrm{GmbH}$, and separately installed by Beijing Fresenius Kabi Pharmaceutical Co., Ltd.; batch number: 16LC6961) was performed. Propofol dosage was calculated based on LBW $[\mathrm{LBW}$ male $=9720 \times \mathrm{TBW} /(6680+216 \times \mathrm{BMI}), \mathrm{LBW}$ female $=9720 \times \mathrm{TBW} /(8780+244 \times \mathrm{BMI})]$, and the dose of propofol was calculated based on the above-mentioned sequential method. Following the propofol injection, 
Table 1 Comparison of the general conditions of the patients

\begin{tabular}{lcc}
\hline Variable & Group B $(\mathrm{n}=20)$ & Group M $(\mathrm{n}=20)$ \\
\hline Gender (male/female) & $10 / 10$ & $7 / 13$ \\
Age (year) & $42.15 \pm 8.78$ & $45.55 \pm 7.28$ \\
BMl $\left(\mathrm{kg} / \mathrm{m}^{2}\right)$ & $38.29 \pm 2.15$ & $37.14 \pm 2.35$ \\
Lean body mass $(\mathrm{kg})$ & $54.92 \pm 7.44$ & $58.88 \pm 9.39$ \\
\hline
\end{tabular}

BMI, body mass index.

$0.2 \mathrm{mg} / \mathrm{kg}$ of cis-atracurium was administered (Jiangsu Hengrui Pharmaceutical Co., Ltd.; batch number: 17050822) (based on the total weight). After patients had lost consciousness, they were manually assisted with the following ventilation: pure oxygen flow $2 \mathrm{~L} / \mathrm{min}$ and respiratory frequency 20-25 times/min. In our experience, after loss of consciousness, the patients' condition of muscle relaxation was good, and BIS was stable. Endotracheal intubation was consistently performed by the same experienced anesthesiologist under visual laryngoscopy. The inner diameter of the endotracheal intubations for male and female patients was 7.5 and $7.0 \mathrm{~mm}$, respectively. After the position of the trachea catheter had been determined, the Drager anesthesia machine was connected for mechanical ventilation with a breathing frequency of 10-12 times/min, a ratio of aspiration to aspiration of 1:2-2.5, a tidal volume of $6-8 \mathrm{~mL} / \mathrm{kg}$, and with the respiratory parameters being set to maintain the carbon dioxide at the end of respiration between $35-45 \mathrm{mmHg}(1 \mathrm{mmHg}=0.133 \mathrm{kPa})$.

\section{Management of special cases}

In cases where the anesthetic depth of the patient did not meet the requirements of intubation, an appropriate amount of propofol was added after the data had been recorded to ensure the anesthetic depth met the requirements of intubation. Patients with severe hypotension during induction were administered $6 \mathrm{mg}$ of ephedrine to raise BP after the data had been recorded.

The study was entirely double-blinded, with the study planner responsible for management of anesthesia, propofol dose regulation, and statistical treatment of all enrolled patients. Another doctor with an unknown propofol dose judged the negative or positive reactions informed by the same criteria.

\section{Observation index}

The heights, weights, ages, gender, and other general information of the patients were recorded. BIS, invasive MAP, and heart rate (HR) at the time of admission were recorded after the concentration of sufentanil reached a stable state of $0.5 \mathrm{ng} / \mathrm{mL}$ target effect-site concentration (Cet) by TCI, after the single intravenous injection of propofol, immediately after intubation, and $1 \mathrm{~min}$ after intubation.

\section{Statistical analysis}

The measurement data was processed with SPSS 20.0 statistical software, and the measurement data was represented by mean \pm standard deviation $(\bar{x} \pm s)$. Comparisons between the counting data groups were conducted by chi-square test. Significance test level alpha $=0.05$ was defined, and statistical significance was considered to exist when $\mathrm{P}<0.05$. Probit regression was used to calculate the EC50 and $95 \%$ confidence interval (CI) of propofol when the reaction was positive.

\section{Results}

\section{General condition of patients in the two groups}

There was no statistically significant difference in the general condition between the two groups $(\mathrm{P}>0.05)$ (Table 1).

\section{Comparison of the signs of patients when entering the room and the signs when sufentanil was infused}

There was no significant difference in vital signs among the 40 patients between basal vital signs and when the concentration of sufentanil reached the set dosage $(P>0.05)$ (Table 2).

\section{Two sequential method}

The sequential method was adopted in group B, and probit 
Table 2 Comparison between the vital signs of the 40 patients after entering the operating room and when the concentration of sufentanil reached the set dosage $(\bar{x} \pm s)$

\begin{tabular}{lcc}
\hline Vital signs & MAP $(\mathrm{mmHg})$ & HR $(\mathrm{bmp})$ \\
\hline Entering the operating room $(\mathrm{n}=40)$ & $100.45 \pm 10.51$ & $84.60 \pm 12.37$ \\
After the infusion of sufentanil $(\mathrm{n}=40)$ & $93.58 \pm 8.58$ & $78.98 \pm 12.59$ \\
\hline
\end{tabular}

MAP, mean arterial pressure; HR, heart rate.

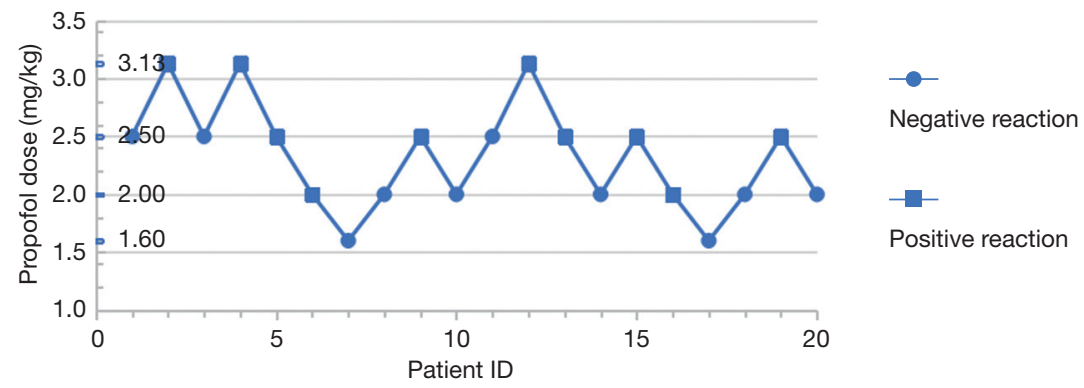

Figure 1 BIS $<50$ positive reaction in group B patients. BIS, bispectral index.

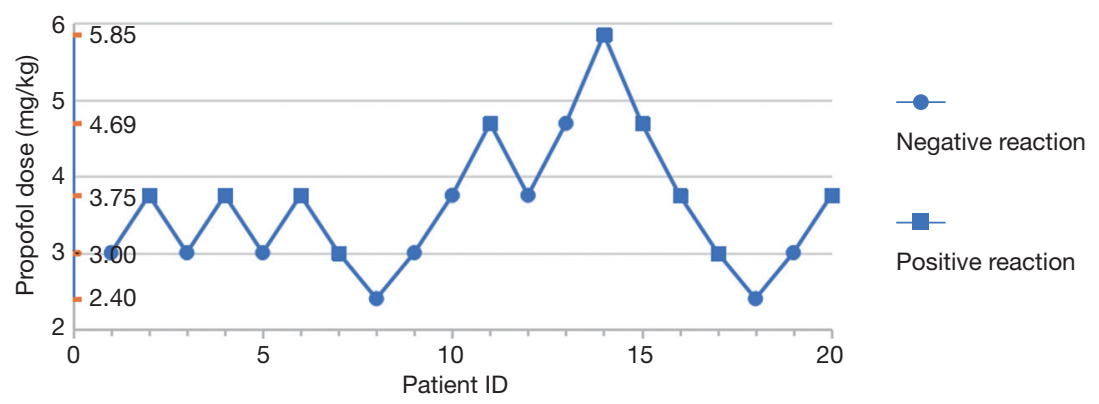

Figure 2 MAP fluctuation amplitude $>40 \%$ positive reaction of the whole process of anesthetic induction in group M. MAP, mean arterial pressure.

regression analysis determined the probit model to be $\mathrm{Y}=-5.411+2.343 \mathrm{X}$ (X was converted by logarithm with base 10). The EC50 of positive reaction of BIS $<50$ was $2.310 \mathrm{mg} / \mathrm{kg}$, and the $95 \%$ CI was $1.850-2.883 \mathrm{mg} / \mathrm{kg}$ (Figure 1).

Probit model $\mathrm{Y}=3.275-0.918 \mathrm{X}$ was obtained by sequential method and probit regression analysis in group $\mathrm{M}$ (X was converted by logarithm with base 10 ). The positive EC50 greater than the whole process of anesthetic induction was $3.567 \mathrm{mg} / \mathrm{kg}$, and the $95 \%$ CI was $1.233-$ $7.165 \mathrm{mg} / \mathrm{kg}$ (Figure 2).

\section{Discussion}

There is a significant increase in cardiac output and absolute circulation in patients with who are morbidly obese $(4,10,11)$, and this affects the early pharmacokinetic parameters of propofol, including apparent volume of distribution. Therefore, morbidly obese patients may be susceptible to drug overdose due to the TBW. Dong et al. $(3,12)$ pointed out that the central ventricular distribution volume (V1) of propofol in morbidly obese patients was comparable to that in patients of a normal weight; however, the peripheral ventricular distribution volume (V2) was $156-180 \%$ higher than that of patients of a normal weight, reaching 73.2-84.2 L. van Kralingen et al. $(13,14)$ observed changes in BIS and hemodynamic parameters associated with total weight and lean body weight, respectively, for anesthesia induction in patients with morbid obesity, and found that cardiovascular stability was improved when 
propofol induction dosage was calculated based on lean body weight. Therefore, at present, lean body weight is considered to be a safer and more effective method on which to base calculations of the propofol induction dose in clinical practice $(15,16)$. In this study, lean body weight was also used as the standard for the dosage of propofol in morbidly obese patients.

In this study, the conditions of endotracheal intubation were achieved by through a combination of sufentanil with propofol for induction. For the purposes of improving comparability between the two groups and eliminating the interference of sufentanil in anesthesia induction $(17,18)$, all patients involved in the study were administered TCI of sufentanil citrate at a concentration of $0.5 \mu \mathrm{g} / \mathrm{mL}$. When the blood concentration of sufentanil reached a stable level, the difference between the blood pressure and heart rate of the patients was insignificant compared with when they entered the room, and so the blood pressure and heart rate of the patients could be used as the base value.

In this study, propofol EC50 with BIS $<50$ was found to be $2.310 \mathrm{mg} / \mathrm{kg}$ in morbidly obese patients during anesthesia induction. It has been demonstrated in previous studies $(4,6,19,20)$ that the amount of propofol needed to induce anesthesia is underestimated due to lean body weight (according to conventional instructions), which often leads to insufficient anesthetic depth and increased risk. Subramani et al. (5) calculated the propofol-induced dose with a LBW of $2.6 \mathrm{mg} / \mathrm{kg}$, which could make the Observer's Assessment of Alertness/Sedation Scale (OAA/S) of patients with morbid obesity reach the median (quarter wise range) $1(0-3)$. This also demonstrated that when morbidly obese patients meet the anesthetic depth, the dosage of propofol exceeds the dose range suggested by conventional instructions.

The results of Wu et al. (21) showed enhanced efficacy or sensitivity of propofol in morbidly obese patients, and that the effect of propofol on cardiovascular depression in patients with morbid obesity was more significant than on patients of a normal weight. The BP fluctuation in patients with morbid obesity during anesthetic induction with propofol was more obvious and common than in normal weight patients. Therefore, a dose of propofol up to $3.567 \mathrm{mg} / \mathrm{kg}$ has been found to reduce the MAP of most patients by $>40 \%$.

Rüsch's (22) results showed that BIS monitoring during the induction of general anesthesia did not act to reduce the incidence and degree of arterial hypotension, and there was no linear correlation between BIS and the decrease of MAP.
With this in mind, current studies do not support the use of BIS as an estimator or guide for doses of anesthetic (23). However, when the EEG dual-frequency index reaches below 50 , the occurrence of adverse cardiovascular reactions during anesthesia induction can be greatly reduced (5-7). Even brief hypotension during anesthesia is associated with tissue hypoperfusion and subsequent complications that can increase postoperative morbidity and mortality (24-26). Hypotension during anesthesia induction is considered to be an independent predictor of adverse clinical outcomes (26). Therefore, the dosage of propofol during anesthesia induction should meet BIS $<50$ while avoiding the decrease of MAP by >by $40 \%$.

After considering the relevant evidence, we conclude that the appropriate anesthetic induction dose of propofol should be $2.310-3.567 \mathrm{mg} / \mathrm{kg}$ in patients with morbid obesity. The dose range in this study is greater than the dose range of patients of normal body size listed in the instructions for propofol. In 2015, The Irish Medical Association also pointed out in its perioperative management guidelines that LBW should be used as the standard for drug dose estimation in morbidly obese patients, but pointed out that, to ensure the avoidance of an insufficient induced dose, a certain proportion of the LBW should be increased. Studies by Janmahasatian and Friesen et al. $(27,28)$ have found that an adjustment between lean weight and total weight after an increase of 1.233 (male) or 1.526 (female) on the basis of lean weight can better balance the problem of insufficient anesthesia and cardiovascular stability during induction. Consequently, the results obtained through this study support anesthetic induction of morbidly obese patients based on thin body weight, but the measurement range was greater than in ordinary patients.

Nevertheless, this study had some limitations. Due to the large individual differences in propofol, the sample size was small, and subsequent studies with a larger sample size are needed to improve the accuracy of the research results.

In summary, when anesthesia is induced by intravenous combined anesthesia, the appropriate dose of propofol for patients with morbid obesity is $2.310-3.567 \mathrm{mg} / \mathrm{kg}$ based on their LBW. This dose can satisfy the intubation depth and ensure that the patient's hemodynamics are stable.

\section{Acknowledgments}

Funding: This work was supported by Xinjiang Uygur Autonomous Region Natural Science Foundation (2017D01C144). 


\section{Footnote}

Reporting Checklist: The authors have completed the CONSORT reporting checklist. Available at http://dx.doi. org/10.21037/apm-20-1223

Data Sharing Statement: Available at http://dx.doi. org/10.21037/apm-20-1223

Conflicts of Interest: All authors have completed the ICMJE uniform disclosure form (available at http://dx.doi. org/10.21037/apm-20-1223). The authors have no conflicts of interest to declare.

Ethical Statement: The authors are accountable for all aspects of the work in ensuring that questions related to the accuracy or integrity of any part of the work are appropriately investigated and resolved. All procedures performed in this study involving human participants were in accordance with the Declaration of Helsinki (as revised in 2013). The study was approved by Ethics Committee of Xinjiang Uygur Autonomous Region People's Hospital (No.: 17-257-KY), and informed consent was signed by the patients and their families.

Open Access Statement: This is an Open Access article distributed in accordance with the Creative Commons Attribution-NonCommercial-NoDerivs 4.0 International License (CC BY-NC-ND 4.0), which permits the noncommercial replication and distribution of the article with the strict proviso that no changes or edits are made and the original work is properly cited (including links to both the formal publication through the relevant DOI and the license). See: https://creativecommons.org/licenses/by-nc-nd/4.0/.

\section{References}

1. Wang H, Wang M, Wang J, et al. Cost-effectiveness analysis of comprehensive intervention programs to control blood glucose in overweight and obese type 2 diabetes mellitus patients based on a real-world setting: Markov modeling. Ann Transl Med 2019;7:676.

2. Cortínez LI, Fuente NDL, Oliveros A, et al. Performance of Propofol Target-Controlled Infusion Models in the Obese: Pharmacokinetic and Pharmacodynamic Analysis. Anesth Analg 2014;119:302-10.

3. Dong D, Peng X, Liu J, et al. Morbid Obesity Alters both Pharmacokinetics and Pharmacodynamics of Propofol:
Dosing Recommendation for Anesthesia Induction. Drug Metab Dispos 2016;44:1579-83.

4. Ingrande J, Brodsky JB, Lemmens HJ. Lean body weight scalar for the anesthetic induction dose of propofol in morbidly obese subjects. Anesth Analg 2011;113:57-62.

5. Subramani Y, Riad W, Chung F, et al. Optimal propofol induction dose in morbidly obese patients: A randomized controlled trial comparing the bispectral index and lean body weight scalar. Can J Anaesth 2017; 64:471-9.

6. Gürses E, Sungurtekin H, Tomatir E, et al. Assessing propofol induction of anesthesia dose using bispectral index analysis. Anesth Analg 2004;98:128-31, table of contents.

7. Arya S, Asthana V, Sharma JP. Clinical vs. bispectral indexguided propofol induction of anesthesia: A comparative study. Saudi J Anaesth 2013;7:75-9.

8. Pandit JJ, Cook TM. Appropriate dosing of lipid-soluble anaesthetics in obese patients: NAP5 recommendations. $\mathrm{Br}$ J Anaesth 2015;115:141-2.

9. Jor O, Maca J, Koutna J, et al. Hypotension after induction of general anesthesia: occurrence, risk factors, and therapy. A prospective multicentre observational study. J Anesth 2018;32:673-80.

10. Avram MJ, Krejcie TC. Using Front-end Kinetics to Optimize Target-controlled Drug Infusions. Anesthesiology 2003;99:1078-86.

11. Han PY, Duffull SB, Kirkpatrick CMJ, et al. Dosing in Obesity: A Simple Solution to a Big Problem. Clin Pharmacol Ther 2007;82:505-8.

12. Albertin A, Poli D, La Colla L, et al. Predictive performance of 'Servin's formula' during BIS-guided propofol-remifentanil target-controlled infusion in morbidly obese patients. Br J Anaesth 2007;98:66-75.

13. van Kralingen S, Diepstraten J, van de Garde EM, et al. Comparative evaluation of propofol 350 and $200 \mathrm{mg}$ for induction of anaesthesia in morbidly obese patients: a randomized double-blind pilot study. Eur J Anaesthesiol 2010;27:572-4.

14. de la Fuente NF, Puga VA, Cortínez LI, et al. The effective effect-site propofol concentration for induction in morbidly obese patients using total body weight with a new pharmacokinetic model. Anesth Analg 2013;117:283-4.

15. Friesen JH. Propofol induction: normalizing the dose in morbidly obese patients. Can J Anaesth 2017;64:456-60.

16. Casati A, Putzu M. Anesthesia in the obese patient: Pharmacokinetic considerations. J Clin Anesth 2005;17:134-45.

17. Luo H, Tao F, Wang GX, et al. Dose-effect relationship of 
shufentanyl in the inhibition of dual-cavity endotracheal intubation response in patients with pulmonary tuberculosis by target-controlled infusion of propofol. Chin J Anaesth 2017;2:199-201.

18. Peng WP, Wang QH, Zuo MZ. Half the effective dose of sufentanil in inhibiting the reaction of double-cavity bronchial catheter intubation when combined with propofol. Chin J Anaesth 2015;12:1470-2.

19. Friesen JH. Lean Body Weight Is Not a Weight Scalar for Estimating Drug Doses in Morbid Obesity. Obes Surg 2015;25:1496-7.

20. Friesen JH. Lean-scaled weight: a proposed weight scalar to calculate drug doses for obese patients. Can J Anaesth 2013;60:214-5.

21. Wu Z, Li J, Wang C, et al. Characterization of cardiovascular depression effect for propofol during anesthesia induction period on morbidly obese patients. Biomed Pharmacother 2018;106:618-23.

22. Rüsch D, Arndt C, Eberhart L, et al. Bispectral index to guide induction of anesthesia: a randomized controlled study. BMC Anesthesiol 2018;18:66.

Cite this article as: Xu G, Qiao N, Pan Y, Simayi A, Chen N. The appropriate dose of propofol for anesthesia induction in morbidly obese patients. Ann Palliat Med 2020;9(4):1921-1927. doi: 10.21037/apm-20-1223
23. Chiravuri D, Owusu-Bediako K, Nafiu OO. Optimal propofol induction dose in morbidly obese patients: bispectral index guidance is not the answer. Can J Anaesth 2018;65:961-2.

24. Bijker JB, Persoon S, Peelen LM, et al. Intraoperative hypotension and perioperative ischemic stroke after general surgery: a nested case-control study. Anesthesiology 2012;116:658-64.

25. Sun LY, Wijeysundera DN, Tait GA, et al. Association of intraoperative hypotension with acute kidney injury after elective noncardiac surgery. Anesthesiology 2015;123:515-23.

26. Green RS, Butler MB. Postintubation Hypotension in General Anesthesia: A Retrospective Analysis. J Intensive Care Med 2016;31:667-75.

27. Janmahasatian S, Duffull SB, Ash S, et al. Quantification of lean bodyweight. Clin Pharmacokinet 2005;44:1051-65.

28. Friesen JH. Estimating the induction dose of propofol in morbid obesity: striking a happy medium. Br J Anaesth 2016;116:730-1. 